\title{
Rhizobium tropici Genes Involved in Free-Living Salt Tolerance are Required for the Establishment of Efficient Nitrogen-Fixing Symbiosis with Phaseolus vulgaris
}

\author{
Joaquina Nogales, ${ }^{1}$ Rosario Campos, ${ }^{2}$ Hanaa BenAbdelkhalek, ${ }^{1,2}$ José Olivares, ${ }^{1}$ Carmen Lluch, ${ }^{2}$ and \\ Juan Sanjuan' \\ ${ }^{1}$ Departamento de Microbiología del Suelo y Sistemas Simbióticos, Estación Experimental del Zaidín, CSIC. Profesor \\ Albareda 1, E-18008 Granada, Spain; ${ }^{2}$ Departamento de Biología Vegetal, Facultad de Ciencias, Universidad de Granada. \\ Campus de Fuentenueva, E-18003 Granada, Spain
}

Submitted 17 May 2001. Accepted 26 November 2001.

\begin{abstract}
Characterization of nine transposon-induced mutants of Rhizobium tropici with decreased salt tolerance (DST) allowed the identification of eight gene loci required for adaptation to high external $\mathrm{NaCl}$. Most of the genes also were involved in adaptation to hyperosmotic media and were required to overcome the toxicity of $\mathrm{LiCl}$. According to their possible functions, genes identified could be classified into three groups. The first group included two genes involved in regulation of gene expression, such as $n t r Y$, the sensor element of the bacterial $n t r Y / n t r X$ two-component regulatory system involved in regulation of nitrogen metabolism, and $g r e A$, which encodes a transcription elongation factor. The second group included genes related to synthesis, assembly, or maturation of proteins, such as alaS coding for alanine-tRNA synthetase, dnaJ, which encodes a molecular chaperone, and a nifS homolog probably encoding a cysteine desulfurase involved in the maturation of Fe-S proteins. Genes related with cellular build-up and maintenance were in the third group, such as a noeJ-homolog, encoding a mannose-1-phosphate guanylyltransferase likely involved in lipopolysaccharide biosynthesis, and kup, specifying an inner-membrane protein involved in potassium uptake. Another gene was identified that had no homology to known genes but that could be conserved in other rhizobia. When inoculated on Phaseolus vulgaris growing under nonsaline conditions, all DST mutants displayed severe symbiotic defects: $n t r Y$ and noeJ mutants were impaired in nodulation, and the remaining mutants formed symbiosis with very reduced nitrogenase activity. The results suggest that bacterial ability to adapt to hyperosmotic and salt stress is important for the bacteroid nitrogen-fixing function inside the legume nodule and provide genetic evidence supporting the suggestion that rhizobia face severe environmental changes after their release into plant cells.
\end{abstract}

Additional keywords: common bean, environmental stress, legumes, salinity.

Corresponding author: J. Sanjuan; Telephone.: +34-958-121011; Fax: +34-958-129600; E-mail: jsanjuan@ eez.csic.es
Leguminous plants are able to establish nitrogen-fixing symbiosis with certain Gram-negative bacteria, collectively known as rhizobia. In the Rhizobium-legume symbiosis, the process of nitrogen fixation is strongly related to the physiological state of the host plant. Therefore, an efficient rhizobial strain is not expected to express its full capacity for nitrogen fixation if limiting factors impose limitations on the vigor of the host legume. Several environmental conditions are limiting factors to the growth and activity of nitrogen-fixing plants. Typical environmental stresses faced by the legume nodules and the symbiotic partners may include water stress, salinity, soil pH, temperature, heavy metals, and so on (Zahran 1999). Salinity is a serious threat to agriculture in arid and semiarid regions. Soil infertility in these areas often is due to the presence of large quantities of salt. Nitrogen-fixing legumes tolerant to salinity represent an important alternative to improve fertility. In general, legumes are more sensitive to salinity than their rhizobial counterparts and, consequently, the symbiosis is more sensitive to salt stress than free-living rhizobia. Salt stress may inhibit the initial steps of the symbiosis (nodule initiation, nodule infection, and development) but it also has a depressive effect on nitrogen fixation (Zahran 1999). Nevertheless, rhizobial tolerance to salinity also is important for the symbiosis. Increasing salt concentrations may have a detrimental effect on rhizobial populations as a result of direct toxicity as well as through osmotic stress. Rhizobia show marked variation in salt tolerance, but it is not clear that salt-tolerant rhizobia are better nitrogen fixers than salt-sensitive ones in saline environments. Many reports have shown that high-tolerant strains are symbiotically more efficient than salt-sensitive ones under salt stress. A major criticism to these reports is that the differences in symbiotic efficiency could have been due to genotypic variations not related to salt tolerance (Zahran 1999). Indeed, few reports have used isogenic or near-isogenic strains with regard to salt tolerance and symbiotic effectiveness. For instance, Chien et al. (1992) described that spontaneous mutants of a salt-sensitive Rhizobium leguminosarum strain with enhanced salt tolerance induced nodules on Vicia faba that lacked nitrogenase activity. In contrast, the work by Ohwada et al. (1998) showed that a transposon-induced mutant of Sinorhizobium fredii with reduced tolerance to $\mathrm{NaCl}$ formed ineffective symbiosis on soybean. In neither of these two cases were the genes involved characterized. Rhizobia may use distinct mechanisms for osmotic adaptation upon salt stress, 
such as the intracellular accumulation of low-molecular-weight organic solutes (osmolytes), including amino acids, sugars, and polyamines, or the accumulation of ions (i.e., $\mathrm{K}^{+}$) (Miller and Wood 1996; Zahran 1999). Other salt-induced responses in rhizobia are changes in cell morphology and size or modifications in the pattern of extracellular polysaccharides (EPS) and lipopolysaccharides (LPS) (Lloret et al. 1995, 1998; Sousi et al. 2001; Zahran 1999). The latter responses may have an impact on the symbiotic interaction because EPS and LPS are very important for the development of root nodules. Nevertheless, response and adaptation to environmental stresses is probably a complex phenomenon involving many physiological and biochemical processes that likely reflect changes in gene expression.

R. tropici CIAT899 is a rhizobial strain that forms effective symbiosis with Phaseolus vulgaris and Leucaena trees (Martínez-Romero et al. 1991). CIAT899 has been shown to tolerate several abiotic stresses, including high temperature, low pH, or salinity (Graham et al. 1994; Riccillo et al. 2000a,b). Our interest was to identify the mechanisms of adaptation of this strain to salinity and to study their possible impact on the establishment of effective symbiosis. In this study, we identified eight different gene loci involved in tolerance of CIAT899 to saline $(\mathrm{NaCl})$ stress. Most of these genes also are required for adaptation to hyperosmotic media. More interestingly, all the genes appear to be very important for the establishment of efficient nitrogen-fixing symbiosis with a legume host.

\section{RESULTS AND DISCUSSION}

Isolation of $\boldsymbol{R}$. tropici mutants with decreased salt tolerance.

Tolerance to $\mathrm{NaCl}$ stress is a very complex phenotype that involves not only the bacterial ability to tolerate the stress but also the swiftness to respond and adapt to the environmental change. Thus, even if strain CIAT899 tolerates well $100 \mathrm{mM}$ $\mathrm{NaCl}$, switching from nonsaline medium to medium with this salt concentration produces some growth delay that is observed during the first 24 to $48 \mathrm{~h}$. Likewise, although strain CIAT899 shows no significant growth on $400 \mathrm{mM} \mathrm{NaCl}$ after 4 days of incubation, it shows certain growth at this and higher salt concentrations if incubation is prolonged. Thus, screening for salt-sensitive mutants must be performed carefully and considering these important premises: salt concentration and incubation period. Strain CIAT899 was subjected to random mutagenesis with the transposon Tn5. A total of 4,000 transposants were screened for inability to grow in media supplemented with $350 \mathrm{mM} \mathrm{NaCl}$ after 3 to 4 days of incubation. Nine mutants which showed decreased salt tolerance (DST) were selected and their growth tested in liquid and solid minimal medium (MM) supplemented with variable amounts of
$\mathrm{NaCl}$. A summary of these results is shown in Table 1. All mutants displayed longer generation times than the wild-type in $\mathrm{NaCl}$-supplemented media, particularly at $300 \mathrm{mM}$ salt, where many mutants showed no appreciable growth. At $100 \mathrm{mM}$ $\mathrm{NaCl}$, all mutants displayed longer duplication times and elapsed lag times compared with the wild-type, indicating that mutations affected both acclimation and growth ability of CIAT899 to saline media. Some mutants (HB1, HB9, and HB13) displayed longer duplication times even in nonsaline media; however, they were selected as DST mutants because their growth was either severely or completely inhibited by $300 \mathrm{mM} \mathrm{NaCl}$ (Table 1). Other mutants, such as HB6, HB8, HB9, and HB10, showed elapsed lag time in nonsaline media, indicating that the mutations slightly affected acclimation of CIAT899 in the transition from rich tryptone-yeast extract-calcium chloride (TY) media to minimal medium.

$\mathrm{NaCl}$ stress involves both osmotic stress and direct ionic toxicity; therefore, we attempted to determine which of these two effects was responsible for the DST phenotype in the mutant strains. The growth rates of the wild type and the mutants on rich TY media containing variable amounts of sucrose (hyperosmotic stress) or $\mathrm{LiCl}$ (ionic toxicity) were compared. Except for strains HB7 (not shown) and HB5, all strains showed increased sensitivity to hyperosmotic media and grew significantly slower than the wild type on media containing $15 \%$ sucrose (Fig. 1). Strains HB6, HB9, and HB13 were the most sensitive to this stress and showed significant growth reduction even on $10 \%$ sucrose (Fig. 1). Thus, except for mutants HB5 and HB7, which carried mutations on the same gene (see below), all other gene loci involved in tolerance to $\mathrm{NaCl}$ also are required for adaptation to osmotic stress induced by high sucrose concentrations. On the other hand, all mutants displayed enhanced sensitivity to the toxic effect of $\mathrm{LiCl}$ and their growth was either severely reduced or completely inhibited by this salt at $100 \mathrm{mM}$ (Fig. 1).

\section{Characterization of $\boldsymbol{R}$. tropici genes involved in tolerance to NaCl.}

Hybridization of genomic DNAs against a Tn5-derived probe showed that all mutants contained a single copy of Tn 5 and that each mutant represented different genomic insertions of the transposon (data not shown). The EcoRI fragments containing the transposon in each mutant were cloned and the Tn5-flanking DNAs sequenced. For each mutant, sequence stretches between $600 \mathrm{nt}$ and more than 1,000 nt were obtained. Sequence analysis and homology searches in the databases allowed the identification of genes interrupted by the Tn5. In mutant HB1, the transposon interrupted a gene encoding a protein highly homologous to histidine kinases belonging

Table 1. Growth parameters of Rhizobium tropici CIAT899 and mutant derivatives on media supplemented with $\mathrm{NaCl}^{\mathrm{a}}$

\begin{tabular}{|c|c|c|c|c|c|c|c|c|}
\hline \multirow[b]{3}{*}{ Strain } & \multicolumn{8}{|c|}{$\mathrm{NaCl}$ concentration $(\mathrm{mM})^{\mathrm{b}}$} \\
\hline & \multicolumn{2}{|c|}{$\mathbf{0}$} & \multicolumn{2}{|c|}{100} & \multicolumn{2}{|c|}{200} & \multicolumn{2}{|c|}{300} \\
\hline & $g$ & lag & $g$ & lag & $g$ & lag & $g$ & lag \\
\hline CIAT899 & 3.8 & 12 & 3.9 & 24 & 5.6 & 36 & 7.9 & 48 \\
\hline HB1 & 5.3 & 24 & 8.1 & 36 & 9.0 & 48 & $-^{c}$ & $>96$ \\
\hline HB5 & 3.6 & 12 & 5.3 & 24 & 9.2 & 48 & 24 & 60 \\
\hline HB7 & 3.6 & 12 & 5.3 & 24 & 8.9 & 36 & 22 & 60 \\
\hline HB6 & 3.8 & 24 & 5.5 & 36 & 8.3 & 60 & - $^{c}$ & $>96$ \\
\hline HB8 & 4.6 & 24 & 8.1 & 48 & - $^{c}$ & 72 & - $^{\mathrm{c}}$ & $>96$ \\
\hline HB9 & 5.1 & 24 & 6.9 & 36 & 9.8 & 48 & $-^{c}$ & $>96$ \\
\hline HB10 & 4.1 & 24 & 6.7 & 36 & 7.9 & 48 & 9.6 & 60 \\
\hline HB12 & 4.8 & 12 & 7.1 & 24 & 9.7 & 48 & $-^{c}$ & $>96$ \\
\hline HB13 & 5.2 & 12 & 9.2 & 24 & 13.4 & 48 & 19 & 60 \\
\hline
\end{tabular}

${ }^{a}$ Cultures grown in minimal media over a $96-\mathrm{h}$ period.

${ }^{\mathrm{b}} \mathrm{g}=$ generation time, in hours and lag $=$ time to resume exponential growth, in hours.

c $-=$ No measurable value. 
to several two-component regulatory systems (Fig. 2). Highest homology was found with NtrY from various rhizobia, the sensor element of the NtrY/NtrX regulatory system involved in nitrogen metabolism and symbiotic nitrogen fixation (Galibert et al. 2001; Kaneko et al. 2000; Pawlowski et al. 1991). Azorhizobium caulinodans $\mathrm{NtrY}^{-}$mutants have decreased ability to utilize several nitrogen sources, including nitrate or glutamate. This could explain why mutant HB1 showed delayed growth even in nonsaline MM (Table 1). Indeed, we could determine that strain HB1 showed delayed growth in media with glutamate, nitrate or ammonium as nitrogen sources, similar to $\mathrm{NtrY}^{-}$strains of A. caulinodans (Fig. $3 \mathrm{~A})$, suggesting that the mutated gene in strain HB1 is indeed the nitrogen regulator $n t r Y$. Our results suggest that this gene is also involved in osmoadaptation of $R$. tropici.

Mutants HB5 and HB7 were found to carry distinct Tn5 insertions on a gene homologous to noeJ from Rhizobium sp. NGR234, encoding mannose-1-phosphate guanylyltransferase (Fig. 2). This enzyme is involved in the biosynthesis of fucose from mannose and probably is required for fucosylation of Nod factors produced by Rhizobium sp. NGR234 (Freiberg et al. 1997). In other bacteria, this protein is involved in polysaccharide biosynthesis (i.e., xanthan by Xanthomonas campestris [Koplin et al. 1992] or alginate in Pseudomonas aeruginosa [Darzins et al. 1986]). R. tropici Nod factors are nonfucosylated (Folch-Mallol et al. 1996; Poupot et al. 1993), it is likely that noeJ in this strain is required for polysaccharide biosynthesis (i.e., EPS or LPS). Fucose is present in the O-antigen of the LPS of CIAT899 (Gil-Serrano et al. 1995) and LPS structure seems to be important for salt tolerance in other rhizobia (Lloret et al. 1995; Soussi et al. 2001; Zahran 1999).

In mutant HB6, the Tn5 interrupted a gene putatively encoding a 118 amino acid (aa) protein of unknown function (orf118, Fig. 2), that shows no homology to proteins described in the databases. Nevertheless, a protein of similar size (116 aa, SMc00655) that shares $75 \%$ sequence identity with Orf118 is described in the annotation of the $S$. meliloti genome (Galibert et al. 2001). Likewise, a protein of unknown function (mlr2817) displaying $60 \%$ identity with Orf118 is encoded in the Mesorhizobium loti genome (Kaneko et al. 2000). This indicates that orf118 may represent a gene conserved among rhizobia.

Analysis of the sequence around the Tn 5 insertion in mutant HB8 identified the C-terminal end of an Orf homologous to Kup, a potassium-uptake system conserved among bacteria and plants. Highest homology (80\% identity in 213 aa) was found with the Kup protein encoded in the Ri plasmid of Agrobacterium rhizogenes (Maeda et al. 1999). In both S. meliloti and $M$. loti, two putative Kup-like systems have been identified (Galibert et al. 2001; Kaneko et al. 2000). In bacteria and plants, $\mathrm{K}^{+}$uptake seems to be mediated by several transport proteins (Kim et al. 1998; Quintero and Blatt 1997). In Escherichia coli, Kup is an inner membrane protein representing a low-affinity $\mathrm{K}^{+}$uptake system, with a minor role in $\mathrm{K}^{+}$transport under normal growth conditions (Schleyer and Bakker 1993). This system, however, seems to be of major importance for $\mathrm{K}^{+}$uptake under hyperosmotic stress at low $\mathrm{pH}$ (Trchounian and Kobayashi 1999). In plants and yeasts, interaction between $\mathrm{K}^{+}$and $\mathrm{Na}^{+}$uptake might play an important role in tolerance to $\mathrm{NaCl}$ (Buschmann et al. 2000; Rios et al. 1997 ) and $\mathrm{K}^{+}$accumulation is one of the various responses observed in rhizobia upon salt stress (Zahran 1999). Thus, the DST phenotype of mutant HB8 could be due to a reduced capacity to accumulate $\mathrm{K}^{+}$in response to high extracellular $\mathrm{Na}^{+}$ and to hyperosmotic stress.

Mutant HB9 carries a Tn5 insertion in the gene alaS, encoding alanyl-tRNA synthetase, which catalyzes the attachment of alanine to the $3^{\prime}$ end of its cognate tRNAs. With few exceptions, single-copy genes code for each aminoacyl-tRNA synthetase in bacteria. Some aminoacyl-tRNA synthetases show no specificity for tRNA recognition, and therefore tRNA ${ }^{\text {Ala }}$ could be charged by other aminoacyl-tRNA synthetases in the absence of AlaS (Martinis and Schimmel 1993). We cannot envisage an specific mechanism for the involvement of AlaS in salt tolerance by CIAT899.

Strain HB10 carries a mutation in a gene homologous to nifS. This gene encodes a cysteine desulfurase that, along with

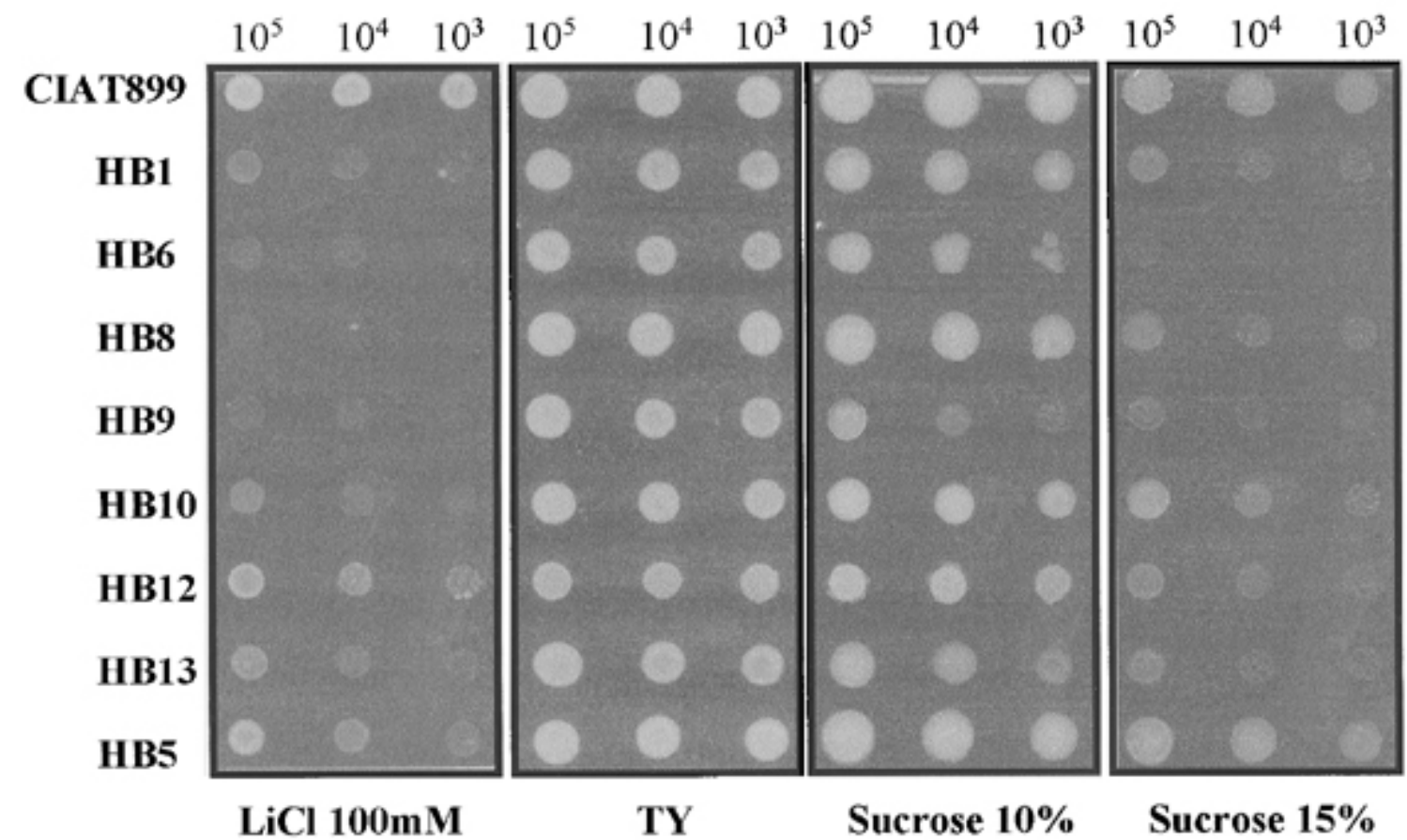

Fig. 1. Growth of Rhizobium tropici CIAT899 and mutant derivatives in rich tryptone-yeast extract-calcium chloride (TY) medium supplemented with LiCl or sucrose. Serial dilutions of indicated strains were spot inoculated on 10 -by-10- $\mathrm{cm}^{2}$ dishes containing agar-TY medium supplemented with indicated compounds. HB7 carried a mutation similar to that of HB5. 
NifU, is required for the formation of Fe-S clusters contained within the nitrogenase component proteins (Yuvaniyama et al. 2000; Zheng et al. 1993). NifS homologs exist in most bacteria and other organisms (Ouzounis and Sander 1993). Proteins of this class play important roles in the maturarion of many $\mathrm{Fe}-\mathrm{S}$ proteins, including transcriptional regulators such as Fnr and SoxR (Hidalgo and Demple 1996; Khoroshilova et al. 1997), and enzymes like biotin synthase (Kiyasu et al. 2000), ferredoxin (Jaschkowitz and Seidler 2000), or phosphoribosylpyrophosphate amidotransferase (Chen et al. 1997). In the absence of other Fe-S cluster assembly proteins, nifS-like and nifU-like genes might be essential for bacterial viability (Olson et al. 2000). A NifS-like protein behaves as a stress-responsive protein in Mycobacterium smegmatis (Murugasu-Oei et al. 1999). Thus, the importance of a nifS-like gene for adaptation of CIAT899 to saline and hyperosmotic media might result from the possible role of this protein in the maturation of $\mathrm{Fe}-\mathrm{S}$ proteins under these conditions.

In mutant HB12, the transposon disrupted the dnaJ gene, encoding the heat-shock responsive molecular chaperone DnaJ. Along with DnaK, DnaJ is involved in protein folding, protein targeting to membranes, and protein renaturation after stress (de Crouy-Chanel et al. 1997). In the halotolerant cyanobacterium Aphanothece halophytica, dnaK expression is increased in response to both heat and hyperosmotic stress (Lee et al. 1997). In Bradyrhizobium japonicum, DnaJ behaves as a heat-shock responsive protein and seems important for growth at supraoptimal temperatures (Minder et al. 1997). A DnaJ-like protein is also involved in hostrange nodulation in $S$. fredii (Krishnan and Pueppke 1991). Mutant HB12 shows reduced growth at $37^{\circ} \mathrm{C}$ (Fig. 3B), indicating that, in addition to its role in salt tolerance, this

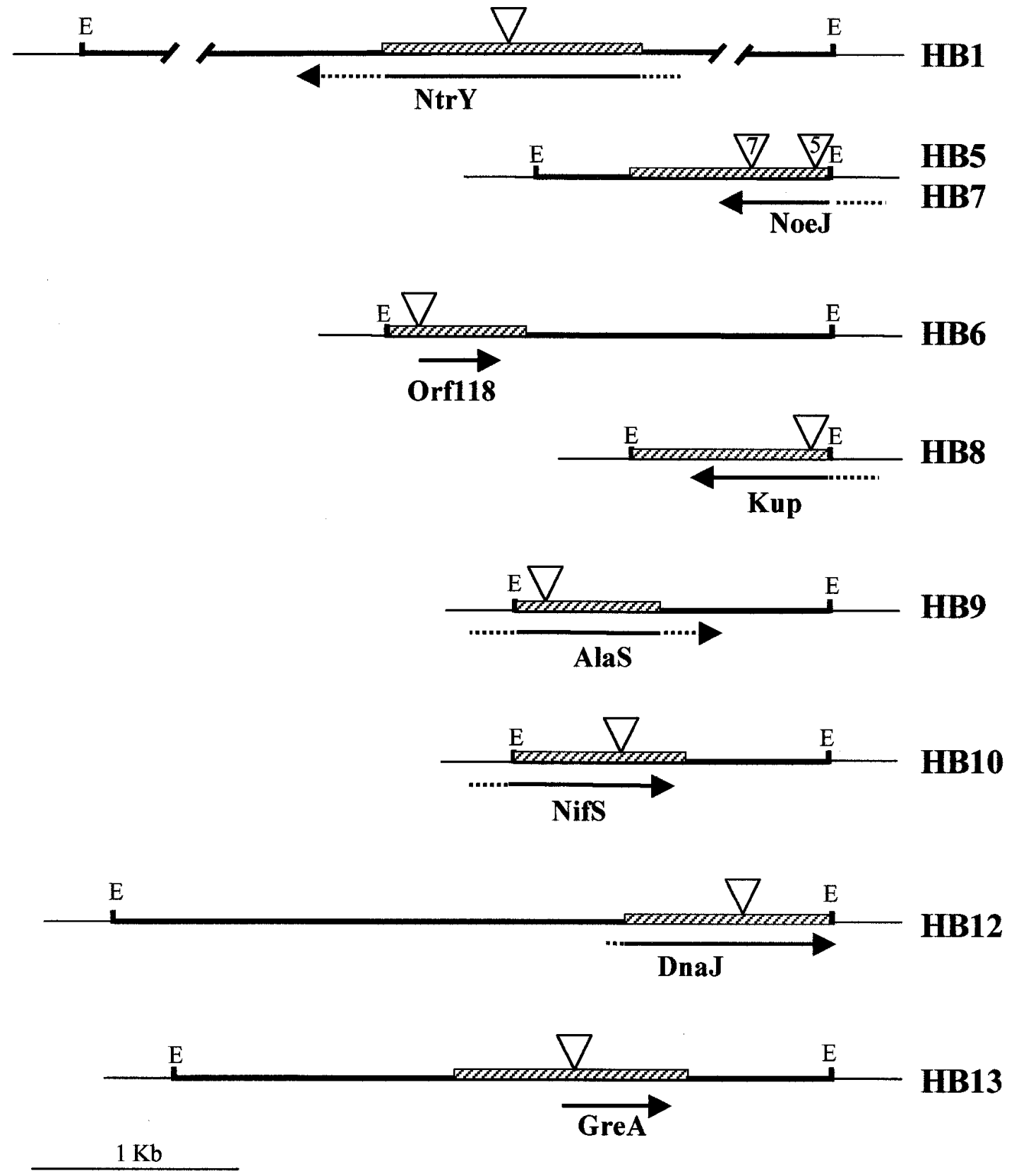

Fig. 2. Characterization of transposon insertions in decreased salt tolerance mutants of CIAT899. The EcoRI (E) fragments containing the transposon (inverted triangles) in each mutant are shown. Dashed bars indicate sequenced stretches around the Tn5 insertions. The open reading frames (ORFs) identified are shown by arrows below each transposon insertion. Orf names are based on sequence homology to known genes. Dashed arrows indicate unknown start or termination points for ORFs. 
gene is also important for growth of CIAT899 at high temperatures.

Finally, mutant HB13 carries a mutation in a gene homologous to greA, encoding a transcription elongation factor that promotes an endogenous transcript cleavage activity of RNA polymerases. GreA activities include suppression of transcription arrest, enhancement of transcription fidelity, and facilitation of the transition from abortive initiation to productive elongation. GreA also promotes elongation through obstructive regions of DNA, including transcription pauses that act as sites of genetic regulation (Marr and Roberts 2000; Toulme et al. 2000). In Bacillus subtilis, GreA has been recognized as a general stress protein (Gsp) induced in response to different environmental conditions such as heat shock, salt stress, and oxidative stress (Volker et al. 1994). It is also possible that GreA is a stress-responsive protein in $R$. tropici and that its activity is required for adequate gene transcription upon salt and osmotic stress.

Although we cannot exclude the possibility that any of the various mutations characterized here may have polar effects on the expression of downstream genes, it can be envisaged from our results that adaptation of CIAT899 to saline and osmotic stress is probably a complex process, involving many different genes. These genes are related to diverse functions, such as gene regulation and expression (ntr $Y$, greA), protein synthesis, assembly and maturation (alaS, dnaJ, nifS), build-up of cellular components like LPS (noeJ), or maintenance of cell integrity through osmotic balance (i.e., $\mathrm{K}^{+}$accumulation $[k u p]$ ). Except for $n t r Y$, greA, and alaS, the genes identified here seem to be of minor importance for growth in nonsaline media. Single mutations led to discrete reductions in tolerance to $\mathrm{NaCl}$ and most of them appeared to be specific for osmotolerance. Therefore, it also is likely that wild-type response and adaptation to high external $\mathrm{NaCl}$ and hyperosmotic media results from the additive and simultaneous action of several different mechanisms switched on upon stress.

\section{DST mutant derivatives of $\boldsymbol{R}$. tropici are defective in symbiosis.}

The efficiency of each DST mutant in symbiosis with Phaseolus vulgaris plants was investigated. P. vulgaris seedlings were inoculated with each mutant and grown in nonsaline nitrogen-free mineral solution. Nodulation, nitrogenase activity, and plant growth parameters were measured 4 weeks after inoculation. After this time, plants inoculated with the wild-type strain CIAT899 had twofold higher dry weight and eightfold higher nitrogen content that noninoculated control plants (Table 2). Surprisingly, all CIAT899-derived mutants showed important symbiotic defects. Mutants HB1, HB5, and HB7 showed severe defects at the level of nodulation, whereas the remaining strains established symbiosis with reduced nitrogen-fixing capacity (Table 2).

Strain HB1, carrying a mutation in a $n t r Y$-like gene, formed no nodules on common beans. Consequently, plants were nitrogen-stressed like the noninoculated controls. This phenotype seems even more drastic than that described for A. caulinodans $\mathrm{NtrY}^{-}$strains, which formed no nodules or Fix ${ }^{\mathrm{d}}$ nodules on the stems or roots of Sesbania rostrata, respectively (Pawlowski et al. 1992). Strains HB5 and HB7, carrying mutations on a noeJ-like gene, both showed a similar phenotype on common beans. Some plants formed no nodules, whereas others formed numerous bumps or tiny nodule-like structures, resembling pseudonodules formed by rhizobial EPS or LPS mutants. As discussed above, it is likely that CIAT899 NoeJ mutants are impaired in the synthesis of some fucose-containing polysaccharide, likely LPS. Based on the symbiotic phenotype, HB5 and HB7 probably are not impaired in EPS production because mutants of CIAT899 altered in EPS biosynthesis have been shown to induce effective nodules on beans (Milner et al. 1992).

The remaining mutants were able to form nodules which looked normal in size and shape compared with wild-type nodules, although two mutants, strains HB6 and HB13, induced significantly fewer nodules than the wild-type strain (Table 2). Nodules formed by mutants HB6, HB8, HB9, HB10, HB12, and $\mathrm{HB} 13$ showed low nitrogenase activity, ranging from 18 to $40 \%$ of that of the wild-type nodules (Table 2). Consequently, all these mutants can be classified as Fix ${ }^{\mathrm{d}}$. This nitrogen fixation defect was further evidenced by a reduced plant growth and a very significant reduction in the nitrogen content of the plant shoots (Table 2). Among the mutants, strains HB9 (AlaS ${ }^{-}$) and HB10 (NifS ${ }^{-}$) performed best in terms of ARA activity and plant growth. The symbiosis induced by strains HB8 $\left(\mathrm{Kup}^{-}\right)$and HB13 $\left(\mathrm{GreA}^{-}\right)$on common beans were virtually Fix $^{-}$. Although these nodules still showed some nitrogenase activity (18\% of the wild type), this appeared insufficient to improve plant growth or nitrogen content above the noninoculated controls (Table 2). Strain HB12, carrying a mutation in dnaJ, formed nodules that expressed less than $25 \%$ ARA activity of wild-type nodules. This result is in contrast with $B$. ja-
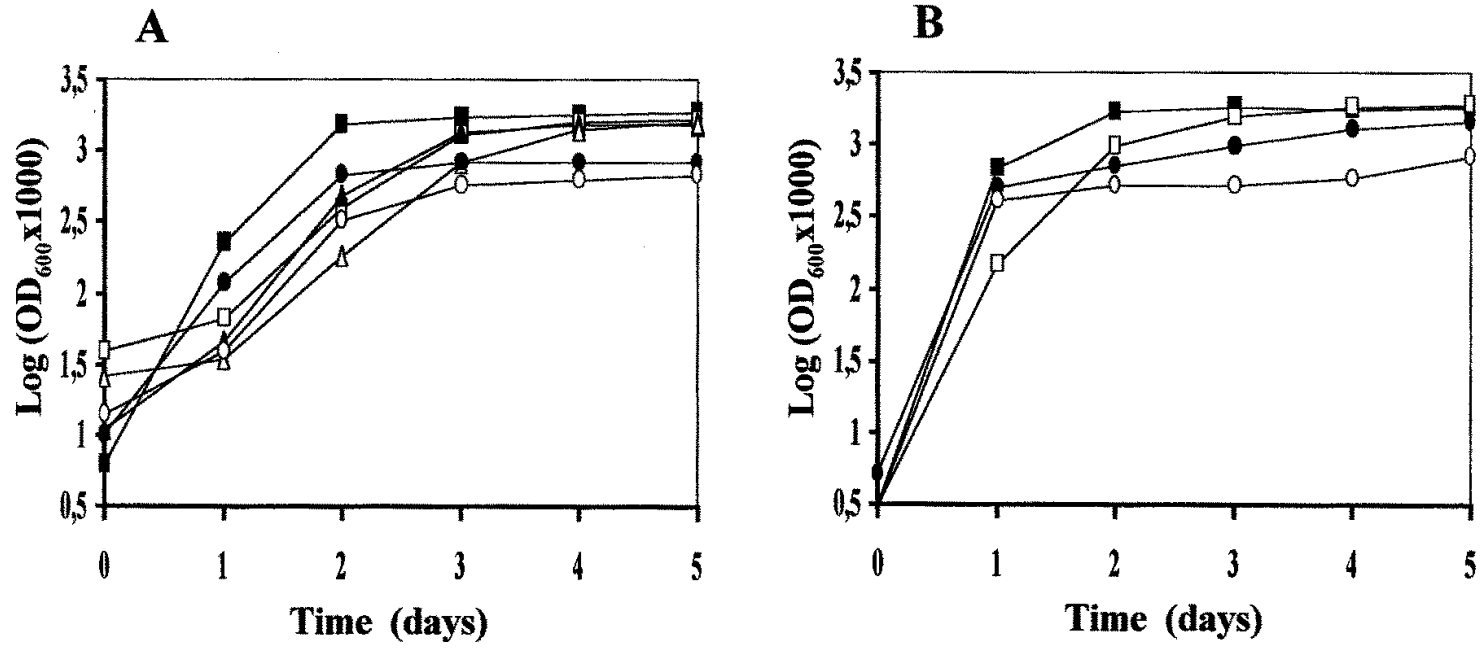

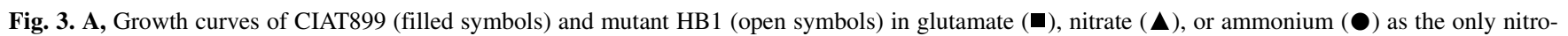
gen source. B, Growth curves of CIAT899 (filled symbols) and mutant derivative $\mathrm{HB} 12$ (open symbols) in minimal medium at $28^{\circ} \mathrm{C}(\mathbf{\square})$ or $37^{\circ} \mathrm{C}(\boldsymbol{O})$. 
ponicum DnaJ ${ }^{-}$strains, which have been shown to establish fully effective symbiosis with soybeans (Minder et al. 1997), but lines up with the fact that $d n a K$ is required for optimum symbiotic function in $S$. meliloti (Summers et al. 1998). As shown above, dnaJ in $R$. tropici CIAT899 might be responsive to at least two different stresses, namely heat and osmotic stress.

It was intriguing that all DST mutants, which had been originally selected for decreased salt tolerance under free-living conditions, were also symbiotically deficient. Mutants HB1, $\mathrm{HB} 5$, and HB7 certainly were impaired in nodulation, and this could result from additional effects of the mutations on nodule formation and development. In contrast, the other six mutants were able to induce nodules that were quite similar to those induced by the wild-type strain, but with significantly lower nitrogenase activity. This implies that the genes involved also are required for bacteroid development or function. This fact might be purely coincidental and could respond to individual, unrelated roles of these genes in the physiology and metabolism of the bacteroid, the nitrogen-fixing form of rhizobia. There is at least one example of mutations impairing osmotolerance that apparently do not affect symbiotic nitrogen fixation. Indeed, biosynthesis of glutathione by CIAT899 has been reported to be important for adaptation to several abiotic stresses, including osmotic stress, but Gsh ${ }^{-}$mutants (unable to synthesize glutathione) form fully effective symbiosis (Riccillo et al. 2000). Nevertheless, externally supplied glutathione improved adaptation of Gsh strains to these stresses, and plants might provide glutathione to the bacteroid, as this compound is very abundant in legume nodules (Matamoros et al. 1999). In spite of the above, and since most of the genes identified here are involved in bacterial adaptation to stress conditions (osmotic and salt stress), it does not seem unreasonable to think that they all may serve the same goal in the bacteroid state. This would lead to the hypothesis that bacteroids may perceive the symbiosome compartment like a stressful environment and that adapting the bacteroid metabolism to this environment involves at least some of the mechanisms active in the free-living state. In agreement with this suggestion, it has been previously proposed that rhizobia encounter severe environmental changes during bacteroid development within plant cells. Modifications on the bacterial cell surface upon release into plant cells are considered as adaptive responses to the environmental changes that bacteria experience within plant cells (Brewin 1998). In addition, the S. meliloti bacA

Table 2. Symbiotic and growth parameters of Phaseolus vulgaris plants inoculated with CIAT899 or decreased salt tolerance mutant derivatives

\begin{tabular}{lrcccc}
\hline Strain & NN $^{\mathbf{a}}$ & NFW $^{\mathbf{b}}$ & ARA $^{\mathbf{c}}$ & SDW $^{\mathbf{d}}$ & N content $^{\mathbf{e}}$ \\
\hline None & $-^{\mathrm{f}}$ & $-^{\mathrm{f}}$ & $-^{\mathrm{f}}$ & 0.86 & 7.50 \\
CIAT899 (w.t.) & 374 & 5.40 & 7.44 & 1.81 & 59.75 \\
HB1 (ntrY) & 0 & $--^{\mathrm{f}}$ & $-_{\mathrm{f}}^{\mathrm{f}}$ & 0.81 & 7.82 \\
HB5 (noeJ) & 0 & $-{ }^{\mathrm{f}}$ & $--^{\mathrm{f}}$ & 0.98 & 7.95 \\
HB7 (noeJ) & 0 & $-{ }^{\mathrm{n}}$ & 3.02 & 0.90 & 7.54 \\
HB6 (orf118) & 166 & 7.24 & 17.97 \\
HB8 (kup) & 224 & 4.59 & 1.33 & 0.78 & 8.88 \\
HB9 (alaS) & 290 & 6.50 & 2.37 & 1.17 & 19.70 \\
HB10 (nifS) & 290 & 5.64 & 2.65 & 1.19 & 37.40 \\
HB12 (dnaJ) & 239 & 5.84 & 1.65 & 0.99 & 15.59 \\
HB13 (greA) & 176 & 5.72 & 1.36 & 0.83 & 10.29 \\
LSD (0.05) & 97 & 2.07 & 1.30 & 0.25 & 1.39 \\
\hline
\end{tabular}

${ }^{a}$ Average number of nodules plant ${ }^{-1}$.

${ }^{\mathrm{b}}$ Average nodule fresh weight in milligrams nodule ${ }^{-1}$.

${ }^{c}$ Acetylene reduction activity in micromoles of $\mathrm{C}_{2} \mathrm{H}_{4}$ plant $^{-1} \mathrm{~h}^{-1}$.

${ }^{\mathrm{d}}$ Shoot dry weight in grams plant ${ }^{-1}$.

${ }^{\mathrm{e}}$ Total nitrogen content in milligrams shoot ${ }^{-1}$.

$\mathrm{f}-=$ No measurable value.

${ }^{\mathrm{g}} \mathrm{LSD}=$ least significant difference. gene, crucial for bacterial differentiation into bacteroids, has been proposed to play a role in adaptation of bacteria to the environmental changes they face upon release into plant cells (Ichige and Walker 1997). Further, there is reported evidence that rhizobia must cope with oxidative stress throughout the process of symbiotic establishment. Bacterial inability to tolerate oxidative stress, as in SodA $\mathrm{A}^{-}$mutants, leads to important symbiotic defects in the $S$. meliloti-alfalfa symbiosis, including reduced nodulation, impaired infection, decreased nitrogenase activity, and arrested bacteroid differentiation (Santos et al. 2000). In this context, our work provide genetic evidence that nitrogen-fixing bacteroids may be under osmotic stress within the host cell. Osmotic stress has not yet been described for symbiotic rhizobia and it seems premature to speculate about the molecular nature of this stress until additional physiological evidence is provided. Nevertheless, our data strongly suggest that bacterial ability to adapt to hyperosmotic and salt stress is important for the bacteroid nitrogen-fixing function inside the legume nodules.

\section{MATERIALS AND METHODS}

\section{Bacteria and growth conditions.}

R. tropici CIAT899 is a wild-type strain $\mathrm{Nod}^{+} \mathrm{Fix}^{+}$on Phaseolus vulgaris (Martínez-Romero et al. 1991). Rhizobial strains were routinely grown at $28^{\circ} \mathrm{C}$ on TY medium or in MM containing glutamate, mannitol, and mineral salts (HerreraCervera et al. 1996). E. coli strains were grown at $37^{\circ} \mathrm{C}$ in Luria broth (LB) medium. When needed, antibiotics were added at the following concentrations: kanamycin (Km), 100 $\mu \mathrm{g} / \mathrm{ml}$ for Rhizobium or $50 \mu \mathrm{g} / \mathrm{ml}$ for E. coli; ampicillin (Ap), $200 \mu \mathrm{g} / \mathrm{ml}$.

\section{Random transposon mutagenesis and selection of mutants.}

Transposon Tn5 mutagenesis of $R$. tropici CIAT899 was carried out following the procedure described by Simon et al. (1983), using strain S17-1 carrying pSUP2021 as donor. Transconjugants were selected on MM plates supplemented with Km. Transposants with DST were selected after replica plating of Km-resistant colonies on MM with or without 350 $\mathrm{mM} \mathrm{NaCl}$ and incubation for $96 \mathrm{~h}$. Growth of selected strains was further tested in liquid MM supplemented or not with 100 , 200 , or $300 \mathrm{mM} \mathrm{NaCl}$. Starting inocula contained approximately $10^{6}$ cells from overnight TY cultures. Cultures were incubated at 28 to $30^{\circ} \mathrm{C}$ in a shaker $(180 \mathrm{rpm})$ and the optical density at 600 nanometers $\left(\mathrm{OD}_{600}\right)$ of the cultures recorded every $12 \mathrm{~h}$. Graphics were constructed in which the logarithm of the $\mathrm{OD}_{600}$ was plotted against time. Generation times were estimated by determining the time required for the $\mathrm{OD}_{600}$ to double, as previously described (Miller 1972). Salt tolerance tests in solid medium was done by streaking a drop containing approximately $10^{5}$ cells of each strain on agar-MM plates supplemented with increasing amounts of $\mathrm{NaCl}(100,150,200$, $250,300,350$, and $400 \mathrm{mM})$. Growth was recorded every 24 h. Tolerance to $\mathrm{LiCl}$ and hyperosmotic media was determined by spot inoculation of 10-fold serial dilutions of each strain on TY plates containing different amounts of sucrose or $\mathrm{LiCl}$, followed by incubation at 28 to $30^{\circ} \mathrm{C}$ for 72 to $96 \mathrm{~h}$.

\section{DNA isolation and manipulation.}

Genomic and plasmid DNAs were isolated using Genomictip 20/G and miniprep Kits (Qiagen, Hilden, Germany), respectively. Restriction endonucleases were used according to manufacturer's instructions (Roche, Mannheim, Germany). For DNA hybridizations, digested DNAs were electrophoresed on agarose gels and transferred to positively charged nylon membranes by the method of Southern (1975). DNA hybridi- 
zation probes were digoxigenin labeled according to standard protocols (Roche). Hybridizations and membrane washes were carried out under high-stringency conditions. Membranes were prepared for chemiluminescence detection (Roche) and exposed to Kodak X-Omat film. The Tn5-containing fragments from mutant strains were cloned into pUC18 after ligation of EcoRI-digested genomic DNAs and transformation of DH5 $\alpha$ competent cells. Transformants were selected in LB supplemented with Ap and Km. EcoRI-BamHI subclones were generated for sequencing DNA from both Tn5 ends. DNA sequencing was carried out with a Perkin-Elmer ABI Prism 373 automated sequencer. Tn5-flanking DNAs were single-strand sequenced using a transposon derived primer. When appropriate, vector- or sequence-derived primers were used. The Genetics Computer Group (University of Wisconsin) package was used in sequence analysis. Blast searches were performed through the NCBI or the EBI servers. The nucleotide sequences reported here are available at the EMBL database under accession numbers AJ311180 to AJ311187.

\section{Plant tests.}

Phaseolus vulgaris L. cv. Contender seeds were surface sterilized by treatment with $4 \%$ sodium hypochlorite for 5 min. Seeds were thoroughly washed, imbibed in water for $2 \mathrm{~h}$, and deposited on vermiculite seedbeds and incubated at $25^{\circ} \mathrm{C}$ in the dark for $48 \mathrm{~h}$. Seedlings were placed on Leonard-type jars (Leonard 1943) containing vermiculite and nitrogen-free mineral solution (Rigaud and Puppo 1975) and inoculated with bacteria at the time of planting. Plants were grown in a growth chamber under a cycle of $16 \mathrm{~h}$ light and $8 \mathrm{~h}$ dark at day and night temperatures of 25 and $17^{\circ} \mathrm{C}$, respectively, and a relative humidity of 55 to $75 \%$. Nitrogenase activity was determined by acetylene reduction on nodulated root portions of six plants, as described previously (Silsbury and Silsbury 1990). The nodulated root sample ( $1 \mathrm{~g}$ of root plus nodules) of each plant was incubated at room temperature in vials containing $\mathrm{C}_{2} \mathrm{H}_{2}(10 \%, \mathrm{vol} / \mathrm{vol})$ in air and sealed with serum caps. Aliquots of $0.2 \mathrm{ml}$ were taken after 5 and $10 \mathrm{~min}$ of incubation and analyzed for ethylene in a Perkin-Elmer 8600 gas chromatography equipped with a Poropak R column (Ligero et al. 1986). Nitrogen content was determined by the Kjeldahl method as described by Brouat and Crouzet (1965). Statistics were performed as previously described (Soussi et al. 1999) The experimental layout was a randomized block design. All values are means of eight replicates per treatment, and the results were subjected to a two-way analysis of variance with the least significant difference test between means.

\section{ACKNOWLEDGMENTS}

This work was supported by the Spanish Ministry of Education and Culture grants PB95-0083 and BIO99-0904 to J. Sanjuan, and grant PB981276 to C. Lluch. Support from the PAI-II programme of the Junta de Andalucia (Spain) is also acknowledged.

\section{LITERATURE CITED}

Brewin, N. J. 1998. Tissue and cell invasion by Rhizobium: the structure and development of infection threads and symbiosomes. Pages 417-429 in: The Rhizobiaceae, Molecular Biology of a Model Plant-Associated Bacteria. H. P. Spaink, A. Kondorosi, and P. J. J. Hooykaas, eds. Kluwer Academic Publishers, Dordrecht, The Netherlands.

Brouat, A., and Crouzet, C. 1965. Notes techniques sur un appareil semiautomatique de clorage de l'azote et de certains composés volatiles. Plant Physiol. 58:438-446.

Buschmann, P. H., Vaidyanathan, R., Gassmann, W., and Schroeder, J. I. 2000. Enhancement of $\mathrm{Na}^{+}$uptake currents, time-dependent inward-rectifying $\mathrm{K}^{+}$channel currents, and $\mathrm{K}^{+}$channel transcripts by $\mathrm{K}^{+}$starvation in wheat root cells. Plant Physiol. 122:1387-1397.

Chen, S., Zheng, L, Dean, D. R., and Zalkin, H. 1997. Role of NifS in maturation of glutamine phosphoribosylpyrophosphate amidotransferase. J. Bacteriol. 179:7587-7590.

Chien, C. T., Maundu, J., Cavanes, J., Dandurand, L. M., and Orser, C. S. 1992. Characterization of salt-tolerant and salt-sensitive mutants of Rhizobium leguminosarum biovar viciae strain C1204b. FEMS Microbiol. Lett. 69:135-140.

Darzins, A., Frantz, B., Vanags, R. I., and Chakrabarty, A. M. 1986. Nucleotide sequence analysis of the phosphomannose isomerase gene (pmi) of Pseudomonas aeruginosa and comparison with the corresponding Escherichia coli gene manA. Gene 42:293-302.

de Crouy-Chanel, A., Hodges, R. S., Kohiyama, M., and Richarme, G. 1997. DnaJ potentiates the interaction between DnaK and alpha-helical peptides. Biochem. Biophys. Res. Commun. 233:627-630.

Folch-Mallol, J. L., Marroquí, S., Sousa, C., Manyani, H., López-Lara, I. M., van der Drift, K. M., Haverkamp, J., Quinto, C., Gil-Serrano, A., Thomas-Oates, J., Spaink, H. P., and Megías, M. 1996. Characterization of Rhizobium tropici CIAT899 nodulation factors: the role of nodH and nodPQ genes in their sulfation. Mol. Plant-Microbe Interact. 9:151-163.

Freiberg, C., Fellay, R., Bairoch, A., Broughton, W. J., Rosenthal, A., and Perret, X. 1997. Molecular basis of symbiosis between Rhizobium and legumes. Nature 387:394-401.

Galibert, F., Finan, T. M., Long, S. R., Pühler, A., et al. 2001. The composite genome of the legume symbiont Sinorhizobium meliloti. Science 293:668-672.

Gil-Serrano, A. M., González-Jiménez, I., Tejero-Mateo, P., JiménezBarbero, J., Megías, M., and Romero-Vázquez, M. J. 1995. Structural analysis of the O-antigen of the lipopolysaccharide of Rhizobium tropici CIAT899. Carbohydr. Res. 275:285-294.

Graham, P. H., Draeger, K. J., Ferrey, M. L., Conroy, M. J., Hammer, B. E., Martinez, E., Aarons, S. R., and Quinto, C. 1994. Acid pH tolerance in strains of Rhizobium and Bradyrhizobium and initial studies on the basis for acid tolerance of Rhizobium tropici UMR 1899. Can. J. Microbiol. 40:198-207.

Herrera-Cervera, J. A., Olivares, J., and Sanjuan, J. 1996. Ammonia inhibition of plasmid pRmeGR4a conjugal transfer between Rhizobium meliloti strains. Appl. Environ. Microbiol. 62:1145-1150.

Hidalgo, E., and Demple, B. 1996. Activation of SoxR-dependent transcription in vitro by noncatalytic or NifS-mediated assembly of [2Fe2S] clusters into apo-SoxR. J. Biol. Chem. 271:7269-7272.

Ichige, A., and Walker, G. C. 1997. Genetic analysis of the Rhizobium meliloti bacA gene: functional interchangeability with the Escherichia coli sbmA gene and phenotype of mutants. J. Bacteriol. 179:209-216.

Jaschkowitz, K., and Seidler, A. 2000. Role of a NifS-like protein from the cyanobacterium Synechocystis PCC6803 in the maturation of FeS proteins. Biochemistry 39:3416-3423.

Kaneko, T., Nakamura, Y., Sato, S., Asamizu, E., et al. 2000. Complete genome structure of the nitrogen-fixing symbiotic bacterium Mesorhizobium loti. DNA Res. 7:331-338.

Khoroshilova, N., Popescu, C., Munck, E., Beinert, H., and Kiley, P. J. 1997. Iron-sulfur cluster disassembly in the FNR protein of Escherichia coli by $\mathrm{O}_{2}$ : $(4 \mathrm{Fe}-4 \mathrm{~S})$ to $(2 \mathrm{Fe}-2 \mathrm{~S})$ conversion with loss of biological activity. Proc. Natl. Acad. Sci. USA 94:6087-6092.

Kim, E. J., Kwak, J. M., Uozumi, N., and Schroeder, J. I. 1998. AtKUP1: an Arabidopsis gene encoding high-affinity potassium transport activity. Plant Cell 10:51-62.

Koplin, R., Arnold, W., Hotte, B., Simon, R., Wang, G., and Pühler, A. 1992. Genetics of xanthan production in Xhantomonas campestris: the $x a n A$ and $x a n B$ genes are involved in UDP-glucose and GDP-mannose biosynthesis. J. Bacteriol. 174:191-199.

Krishnan, H. B., and Pueppke, S. G. 1991. nolC, a Rhizobium fredii gene involved in cultivar-specific nodulation of soybean, shares homology with a heat-shock gene. Mol. Microbiol. 5:737-745.

Lee, B. H., Hibino, T., Jo, J., Viale, A. M., and Tabake, T. 1997. Isolation and characterization of a dnaK genomic locus in a halotolerant cyanobacterium Aphanothece halophytica. Plant Mol. Biol. 35:763-775.

Leonard, L. T. 1943. A simple assembly for use in testing of culture of rhizobia. J. Bacteriol. 45:523-527.

Ligero, F., Lluch, C., and Olivares, J. 1986. Evolution of ethylene from root of Medicago sativa plants inoculated with Rhizobium meliloti. J. Plant Physiol. 125:361-365.

Lloret, J., Bolaños, L., Lucas, M. M., Peart, J. M., Brewin, N. J., Bonilla, I., and Rivilla, R. 1995. Ionic stress and osmotic pressure induce different alterations in the lipopolysaccharide of a Rhizobium meliloti strain. Appl. Environ. Microbiol. 61:3701-3704.

Lloret, J., Wulff, B. B., Rubio, J. M., Downie, J. A., Bonilla, I., and Rivilla, R. 1998 Exopolysaccharide II production is regulated by salt in the halotolerant strain Rhizobium meliloti EFB1. Appl. Environ. Microbiol. 64:1024-1028.

Maeda, Y., Moriguchi, K., Kataoka, M., Satou, M., Satutui, N., Tanaka, N., and Yoshida, K. 1999. Genome structure of Ri plasmid. Sequencing 
analysis of T-DNA and its flanking regions of pRi1724 in Japanese Agrobacterium rhizogenes. Nucleic Acids Symp. Ser. 42:67-68.

Marr, M. T., and Roberts, J. W. 2000. Function of transcription cleavage factors GreA and GreB at a regulatory pause site. Mol. Cell 6:12751285 .

Martínez-Romero, E., Segovia, L., Mercante, F. M., Franco, A. A., Graham, P., and Pardo, M. 1991. Rhizobium tropici, a novel species nodulating Phaseolus vulgaris L. beans and Leucaena sp. Tress. Int. J. Syst. Bacteriol. 41:417-426.

Martinis, S. A., and Schimmel, P. 1993. Aminoacyl-tRNA synthetases: general features and relationships. Pages 887-901 in: Escherichia coli and Salmonella, Cellular and Molecular Biology. 2nd ed. F. C. Neidhardt, ed. American Society for Microbiology, Washington, D.C.

Matamoros, M. A., Moran, J. F., Iturbe-Ormaetxe, I., Rubio, M. C., and Becana, M. 1999. Glutathione and homoglutathione synthesis in legume root nodules. Plant Physiol. 121:879-888.

Miller, J. H. 1972. Experiments in Molecular Genetics. Cold Spring Harbor Laboratory, Cold Spring Harbor, NY.

Miller, K. J., and Wood, J. M. 1996. Osmoadaptation by rhizosphere bacteria. Annu. Rev. Microbiol. 50:101-136.

Milner, J. L., Araujo, R. S., and Handelsman, J. 1992. Molecular and symbiotic characterization of exopolysaccharide-deficient mutants of Rhizobium tropici strain CIAT899. Mol. Microbiol. 6:3137-3147.

Minder, A. C., Narberhaus, F., Babst, M., Hennecke, H., and Fischer, H. M. 1997. The dnaKJ operon belongs to the sigma32-dependent class of heat shock genes in Bradyrhizobium japonicum. Mol. Gen. Genet. 254:195-206.

Murugasu-Oei, B., Tay, A., and Dick, T. 1999. Upregulation of stress response genes and $\mathrm{ABC}$ transporters in anaerobic stationary-phase Mycobacterium smegmatis. Mol. Gen. Genet. 262:677-682.

Ohwada, T., Sasaki, Y., Koike, H., Igawa, K., and Sato, T. 1998. Correlation between $\mathrm{NaCl}$ sensitivity of Rhizobium bacteria and ineffective nodulation of leguminous plants. Biosci. Biotechnol. Biochem. 62:2086-2090.

Olson, J. W., Agar, J. N., Johnson, M. K., and Maier, R. J. 2000. Characterization of the NifU and NifS Fe-S cluster formation proteins essential for viability in Helicobacter pylori. Biochemistry 39:16213-16219.

Ouzounis, C., and Sander, C. 1993. Homology of the NifS family of proteins to a new class of pyridoxal phosphate-dependent enzymes. FEBS Lett. 322:159-164.

Pawlowski, K., Klosse, U., and de Bruijn, F. J. 1991. Characterization of a novel Azorhizobium caulinodans ORS751 two-component regulatory system, NtrY/NtrX, involved in nitrogen fixation and metabolism. Mol. Gen. Genet. 231:124-138.

Poupot, R., Martinez-Romero, E., and Prome, J. C. 1993. Nodulation factors from Rhizobium tropici are sulfated or non-sulfated chitopentasaccharides containing an $\mathrm{N}$-methyl-N-acylglucosaminyl terminus. Biochemistry 32:10430-10435.

Quintero, F. J., and Blatt, M. R. 1997. A new family of $\mathrm{K}^{+}$transporters from Arabidopsis that are conserved across phyla. FEBS Lett. 415:201-211.

Riccillo, P. M., Collavino, M. M., Grasso, D. H., England, R., de Bruijn, F. J., and Aguilar, O. M. 2000a. A guaB mutant of Rhizobium tropici CIAT899 pleitropically defective in thermal tolerance and symbiosis.
Mol. Plant-Microbe Interact. 13:1228-1236.

Riccillo, P. M. Muglia, C. I., de Bruijn, F. J., Roe, A. J., Booth, I. R., and Aguilar, O. M. 2000b. Glutathione is involved in environmental stress responses in Rhizobium tropici, including acid tolerance. J. Bacteriol. 182:1748-1753.

Rigaud, J., and Puppo, A. 1975. Indole-3-acetic catabolism by soybean bacteria. J. Gen. Microbiol. 88:223-228.

Rios, G., Ferrando, A., and Serrano, R. 1997. Mechanisms of salt tolerance conferred by overexpression of the HAL1 gene in Saccharomyces cerevisiae. Yeast 13:515-528.

Santos, R., Hérouart, D., Puppo, A., and Touati, D. 2000. Critical protective role of bacterial superoxide dismutase in Rhizobium-legume symbiosis. Mol. Microbiol. 38:750-759.

Schleyer, M., and Bakker, E. P. 1993. Nucleotide sequence and $3^{\prime}$-end deletion studies indicate that the $\mathrm{K}^{+}$-uptake protein Kup from Escherichia coli is composed of a hydrophobic core linked to a large and partially essential hydrophilic C terminus. J. Bacteriol. 175:6925-6931.

Silsbury, H., and Silsbury, J. H. 1990. Estimating nitrogenase activity of faba bean (Vicia faba L.) by acetylene reduction (AR) assay. Aust. J. Plant Physiol. 17:489-502.

Simon, R., Priefer, U., and Pühler, A. 1983. A broad host range mobilization system for in vivo genetic engineering: transposon mutagenesis in gram-negative bacteria. Biotechnology 1:784-789.

Soussi, M., Lluch, C., and Ocaña, A. 1999. Comparative study of nitrogenfixation and carbon metabolism in two chick-pea (Cicer arietinum L.) cultivars under salt stress. J. Exp. Bot. 50:1701-1708.

Soussi, M., Santamaría, M., Ocaña, A., and Lluch, C. 2001. Effects of salinity on protein and lipopolysaccharide pattern in a salt-tolerant strain of Mesorhizobium ciceri. J. Appl. Microbiol. 90:476-481.

Southern, E. M. 1975. Detection of specific sequences among DNA fragments separated by gel electrophoresis. J. Mol. Biol. 98:503-517.

Summers, M. L., Elkins, J. G., Elliot, B. A., and McDermott, T. R. 1998 Expression and regulation of phosphate stress inducible genes in $\mathrm{Si}$ norhizobium meliloti. Mol. Plant-Microbe Interact. 11:1094-1101.

Toulme, F., Mosrin-Huaman, C., Sparkowski, J., Das, A., Leng, M., and Rahmouni, A. R. 2000. GreA and GreB proteins revive backtracked RNA polymerase in vivo by promoting transcript trimming. EMBO J. 19:6853-6859.

Trchounian, A., and Kobayashi, H. 1999. Kup is the major $\mathrm{K}^{+}$uptake system in Escherichia coli upon hyper-osmotic stress at a low pH. FEBS Lett. 447:144-148.

Volker, U., Engelmann, S., Maul, Briethdorf, S., Volker, A., Schmid, R., Mach, H., and Hecker, M. 1994. Analysis of the induction of general stress proteins of Bacillus subtilis. Microbiology 140:741-752.

Yuvaniyama, P., Agar, J. N., Cash, V. L., Johnson M. K., and Dean, D. R. 2000. NifS-directed assembly of a transient (2Fe-2S) cluster within the NifU protein. Proc. Natl. Acad. Sci. USA 97:599-604.

Zahran, H. H. 1999. Rhizobium-legume symbiosis and nitrogen fixation under severe conditions and in an arid climate. Microbiol. Mol. Biol. Rev. 63:968-989.

Zheng, L., White, R. H., Cash, V. L., Jack, R. F., and Dean, D. R. 1993. Cysteine desulfurase activity indicates a role for NifS in metallocluster biosynthesis. Proc. Natl. Acad. Sci. USA 90:2754-2758. 